\title{
BMJ Open Experiences and views of receiving and delivering information about recovery in acquired neurological conditions: a systematic review of qualitative literature
}

\author{
Louisa-Jane Burton (D) , ${ }^{1,2}$ Anne Forster (D) , ${ }^{1,2}$ Judith Johnson (D) ,3,4,5 \\ Thomas F. Crocker (D) ,' Sarah F. Tyson (D) , ${ }^{6}$ Faye Wray (D) , ${ }^{1}$ David J. Clarke (D) ${ }^{1,2}$
}

To cite: Burton L-J, Forster A, Johnson J, et al. Experiences and views of receiving and delivering information about recovery in acquired neurological conditions: a systematic review of qualitative literature. BMJ Open 2021;11:e045297. doi:10.1136/ bmjopen-2020-045297

- Prepublication history and additional supplemental material for this paper are available online. To view these files, please visit the journal online (http://dx.doi.org/10.1136/ bmjopen-2020-045297)

Received 28 September 2020 Revised 01 April 2021 Accepted 09 April 2021
Check for updates

(C) Author(s) (or their employer(s)) 2021. Re-use permitted under CC BY-NC. No commercial re-use. See rights and permissions. Published by BMJ.

For numbered affiliations see end of article.

Correspondence to Ms Louisa-Jane Burton; louisa.burton@bthft.nhs.uk

\section{ABSTRACT}

Objective To review and synthesise qualitative literature relating to the views, perceptions and experiences of patients with acquired neurological conditions and their caregivers about the process of receiving information about recovery; as well as the views and experiences of healthcare professionals involved in delivering this information.

Design Systematic review of qualitative studies. Data sources MEDLINE, Embase, AMED, CINAHL, PsycINFO, Web of Science and the Cochrane library were searched from their inception to July 2019.

Data extraction and synthesis Two reviewers extracted data from the included studies and assessed quality using an established tool. Thematic synthesis was used to synthesise the findings of included studies.

Results Searches yielded 9105 titles, with 145 retained for full-text screening. Twenty-eight studies (30 papers) from eight countries were included. Inductive analysis resulted in 11 descriptive themes, from which 5 analytical themes were generated: the right information at the right time; managing expectations; it's not what you say, it's how you say it; learning how to talk about recovery and manage emotions; the context of uncertainty.

Conclusions Our findings highlight the inherent challenges in talking about recovery in an emotional context, where breaking bad news is a key feature. Future interventions should focus on preparing staff to meet patients' and families' information needs, as well as ensuring they have the skills to discuss potential recovery and break bad news compassionately and share the uncertain trajectory characteristic of acquired neurological conditions. An agreed team-based approach to talking about recovery is recommended to ensure consistency and improve the experiences of patients and their families.

\section{BACKGROUND}

A number of acquired conditions can cause damage to the brain, spine or peripheral nervous system, including traumatic injury, stroke and haemorrhage, with over a million survivors living in the UK alone. ${ }^{1}$ Such disorders have a sudden onset, and if survived, can result in impairments to movement,
Strengths and limitations of this study

- This is the first systematic review of findings from qualitative studies exploring discussions about recovery in the context of acquired neurological conditions, which has integrated and contrasted the experiences and perspectives of patients, their caregivers and healthcare professionals.

- Developing an understanding of the experiences and perceptions of patients, caregivers and healthcare professionals through systematic synthesis of qualitative literature using rigorous methods can inform the development of interventions to improve practice

- Due to the diversity of language used in the field of talking about recovery and breaking bad news, it is possible that we did not identify all titles meeting our inclusion criteria; however, all efforts were made using broad search criteria and backwards and forwards citation searching.

sensation, cognition and communication, with the potential for wide-ranging effects on an individual's daily life. For many survivors, the road to recovery is long, and rehabilitation provided by a multidisciplinary team of doctors, nurses and therapists is recommended. ${ }^{2-5}$

The long-term impact of these events is characterised by uncertainty, ${ }^{6}$ and as they participate in rehabilitation, survivors often have questions about the possibility of returning to their previous lifestyles. Such questions prompt conversations about recovery, which may involve healthcare professionals (HCPs) making and conveying predictions about recovery potential and sometimes breaking bad news. ${ }^{7}$ Bad news has been defined as 'any information that produces a negative alteration to a person's expectations about their present and future' (p312). ${ }^{8}$ The term is often applied in cancer and palliative care, in relation to a life-limiting prognosis. In 
neurological settings, however, these conversations have a somewhat different focus: some recovery is often possible and discussions may relate to whether an individual will regain functions such as movement or continence, be independent in daily life and return to activities they enjoy, or participate in their vocational or social roles. Discussions may be complicated by the inherent uncertainty in neurological recovery, and the potential impact of cognitive or communication difficulties resulting from these conditions, which can require information to be presented in different formats and increased involvement from patients' families. ${ }^{7}$ Despite these challenges, information about recovery is important for individuals to make future plans and potentially adjust to life with long-term disability.

As the science in predicting recovery develops, ${ }^{9-11}$ researchers have increasingly sought to explore and understand discussions about recovery from the perspectives of those who have experienced them, namely the patients and caregivers receiving information and the HCPs who provide it $\left(\mathrm{eg},{ }^{12}\right)$. The use of qualitative methods has generated rich and detailed understanding across a variety of contexts following diagnosis of acquired neurological conditions. However, studies are often small, condition specific and focus on a single group (patients, caregivers or HCPs). Synthesis of qualitative literature facilitates translation of concepts across a range of studies, making their findings accessible to a wider audience and informing clinical practice and policy. ${ }^{13}$ This review aims to bring together and synthesise findings from qualitative studies across acquired neurological conditions, including stroke, traumatic brain injury (TBI), spinal cord injury (SCI) and brain tumour, where similar issues may be encountered, to understand how conversations about recovery are viewed and experienced by patients, their families and HCPs involved in their care. Synthesis of participants' views and experiences from this review will inform our planned development of an intervention to improve conversations about recovery after stroke and would be useful for such interventions in other acquired neurological conditions.

\section{METHODS}

The systematic review protocol was prospectively registered on the International Prospective Register of Systematic Reviews (ref: CRD42017081922) and is reported following 'Enhancing Transparency in Reporting the Synthesis of Qualitative Research' guidelines (see online supplemental file 1). ${ }^{14}$

\section{Search strategy and data management}

Electronic databases including MEDLINE, Embase, AMED, CINAHL, PsycINFO, Web of Science and the Cochrane library were searched from time of inception to end of July 2019. A search strategy was developed with assistance from an information specialist (see online supplemental file 2 for an example search). Studies were eligible if they were published in English language and:

- Reported empirical qualitative research.

- $>50 \%$ of participants were either adults with a diagnosis of an acquired neurological condition (stroke, TBI, SCI, brain/central nervous system tumours), their caregivers or HCPs (including studies where HCPs worked with patients with a range of neurological conditions).

- Reported experiences, views or perceptions of giving and/or receiving information about prognosis or recovery.

There were no restrictions according to setting or time post-diagnosis. Where a paper considered the views of HCPs working across multiple neurological conditions (rather than a specific condition, for example, in neurorehabilitation), these papers were considered suitable for inclusion, as it was deemed that the views of these professionals were relevant to our research question. Previous authors of systematic reviews aiming to identify papers relating to the provision of recovery information and breaking bad news have identified challenges in keyword searching, resulting from the variety of language used in this field,$^{15}$ for example, "prognostic awareness" or "difficult conversations." ${ }^{77}$ We aimed to be as comprehensive as possible in our selection of keywords and, to ensure literature saturation, employed backwards and forwards citation searching of included articles.

Literature search results from each database were combined, and de-duplicated in EndNote. Titles and abstracts were screened for eligibility against the inclusion criteria by the lead author, with $20 \%$ independently screened by a second reviewer (AF). Full texts were obtained for each paper deemed to meet inclusion criteria and for those where there was uncertainty. Fulltext review was conducted by two independent reviewers (L-JB and either FW or a research colleague) using a Microsoft Access database, where reasons for exclusion were recorded. Discrepancies between reviewers were discussed and referred to a third reviewer (DC) where agreement could not be reached.

\section{Quality appraisal}

Critical appraisal of study quality was completed using a checklist covering the core domains of quality in qualitative research (the National Institute for Health and Care Excellence public health guidance quality appraisal checklist ${ }^{18}$ ), which assesses 14 domains including study design and appropriateness of qualitative methods, clarity of the study aims, data collection methods including triangulation, consideration of context, the role of the researcher, analytical methods, conclusions and ethics. Included studies were graded in three categories according to whether all or most of the checklist items were fulfilled $(++)$, some of the items were fulfilled $(+)$, or few or none of the items were fulfilled (-).

Two independent reviewers scored each included study according to the checklist (L-JB and either FW or 
a research colleague). The primary reviewer compared both sets of scores and discussed areas of disagreement with the second reviewer. Where consensus could not be reached, a third reviewer was consulted (JJ). In this study, quality was assessed to reveal possible limitations to included studies, rather than for the purposes of exclusion. We examined the results of lower quality studies to confirm that they did not contradict the findings of higher quality studies, and that these studies did not contribute disproportionately to our conclusions. This was to ensure that the synthesis results were not biased by lower quality studies and therefore lower the risk of drawing unreliable conclusions.

\section{Data extraction and synthesis}

Data were extracted from the selected papers, using a standardised form. Extracted data included study aims, sampling techniques and size, participant demographic information (age, gender, diagnosis), country, study setting and methodology (data collection and analysis methods). Data were extracted from all included studies by two independent reviewers (L-JB and either FW or a research colleague) and compared to check agreement levels.

In addition, all text labelled as 'results' or 'findings', including participant quotations and author-generated analytical themes, was extracted from included studies into qualitative data management software (QSR NVivo V.10). Thematic synthesis ${ }^{13}$ was selected for this study because it can be applied to review questions aiming to make recommendations for interventions, ${ }^{19}$ and moves from initial line-by-line coding of data presented in individual studies, to subsequent development of descriptive, and then analytical themes. Its detailed procedure addresses questions relating to transparency in qualitative synthesis by maintaining a clear link between the findings of primary studies and the review conclusions. ${ }^{13}$

In this study, extracted data were inductively freecoded line-by-line by the primary author. The codes generated were grouped and organised into descriptive themes to form a coding framework, which was subsequently reapplied to the included studies. The coded findings were then displayed in a framework matrix, to facilitate comparison of the views and experiences of HCPs, patients and caregivers; and to assess whether and how views and experiences might vary, depending on neurological condition and participant type. Summaries describing what was important to patients, caregivers and HCPs when talking about recovery were developed for each descriptive theme and the findings of the primary studies were then considered against the review questions to develop analytical themes. This involved interpretation of study findings to develop an understanding of the range of issues that are important to participants when talking about recovery and how these affect behaviour, to make recommendations for the development of a future intervention. This development was iterative and founded upon links between the identified descriptive themes and their implications for how patients, caregivers and HCPs experience the provision and receipt of information about recovery. Preliminary results were discussed among the research team during the coding process, and throughout the development of themes. A draft summary of findings was prepared by L-JB and circulated among the review team, who suggested other potential interpretations. Following amendments, a final stage of reading through all included studies ensured that findings were representative of the original studies.

\section{Patient and public involvement}

Ideas for the design of the studies making up this programme of research were presented at three groups attended by stroke survivors and caregivers (the Consumer Research Advisory Group, and two Stroke Association-run groups in Greater Manchester). Members commented on the importance of the research topic, and highlighted the need to understand the views and experiences of patients and caregivers in developing an intervention. They supported the proposals for the design and conduct of this review.

\section{RESULTS}

Following removal of duplicates, the searches identified 9105 articles for title/abstract screening (see figure 1). Full texts of 145 papers were retrieved for review, and 30 papers reporting 28 studies were retained for inclusion. Two studies were reported in two papers each: Lefebvre and Levert ${ }^{2021}$ and Wiles et al..$^{22} 23$

\section{Study characteristics}

The 28 included studies were conducted in eight different countries: nine in the USA ${ }^{16}{ }^{24-31}$ six in the UK, ${ }^{12} 172223$ 32-34 five in Australia, ${ }^{35-39}$ three in Canada, ${ }^{40-42}$ two in Italy, ${ }^{43} 44$ one each in Sweden ${ }^{45}$ and Turkey, ${ }^{46}$ and one in Canada and France ${ }^{20}{ }^{21}$ (see table 1). Included studies most frequently came from the stroke literature $(\mathrm{n}=10),{ }^{22-24} 27323335363945$ while similar numbers came from TBI $(n=6), 20212526293042$ SCI $(n=5)^{28} 40434446$ and multiple neurological conditions $(\mathrm{n}=5),{ }^{12} 17343741$ with a minority from the brain tumour literature $(n=2) .{ }^{1638}$ Of the five papers considering multiple neurological conditions, four included only HCPs, who worked with patients with a range of neurological diagnoses. These included HCPs working in TBI and SCI rehabilitation, ${ }^{17}$ occupational therapists working in neurology settings, ${ }^{12}$ neurological physiotherapists, ${ }^{34}$ and speech and language therapists working with patients with aphasia. ${ }^{37}$ The latter three papers contained no further information about the diagnoses of the patients with whom the HCPs worked. The fifth paper included patients, carers and HCPs in palliative neurology, citing a range of conditions including stroke, TBI, brain tumours, amyotrophic lateral sclerosis and muscular dystrophies. ${ }^{41}$

Roughly equal numbers took place in the

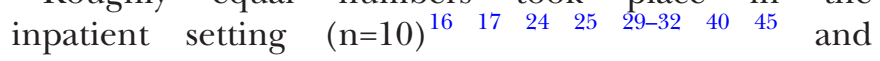




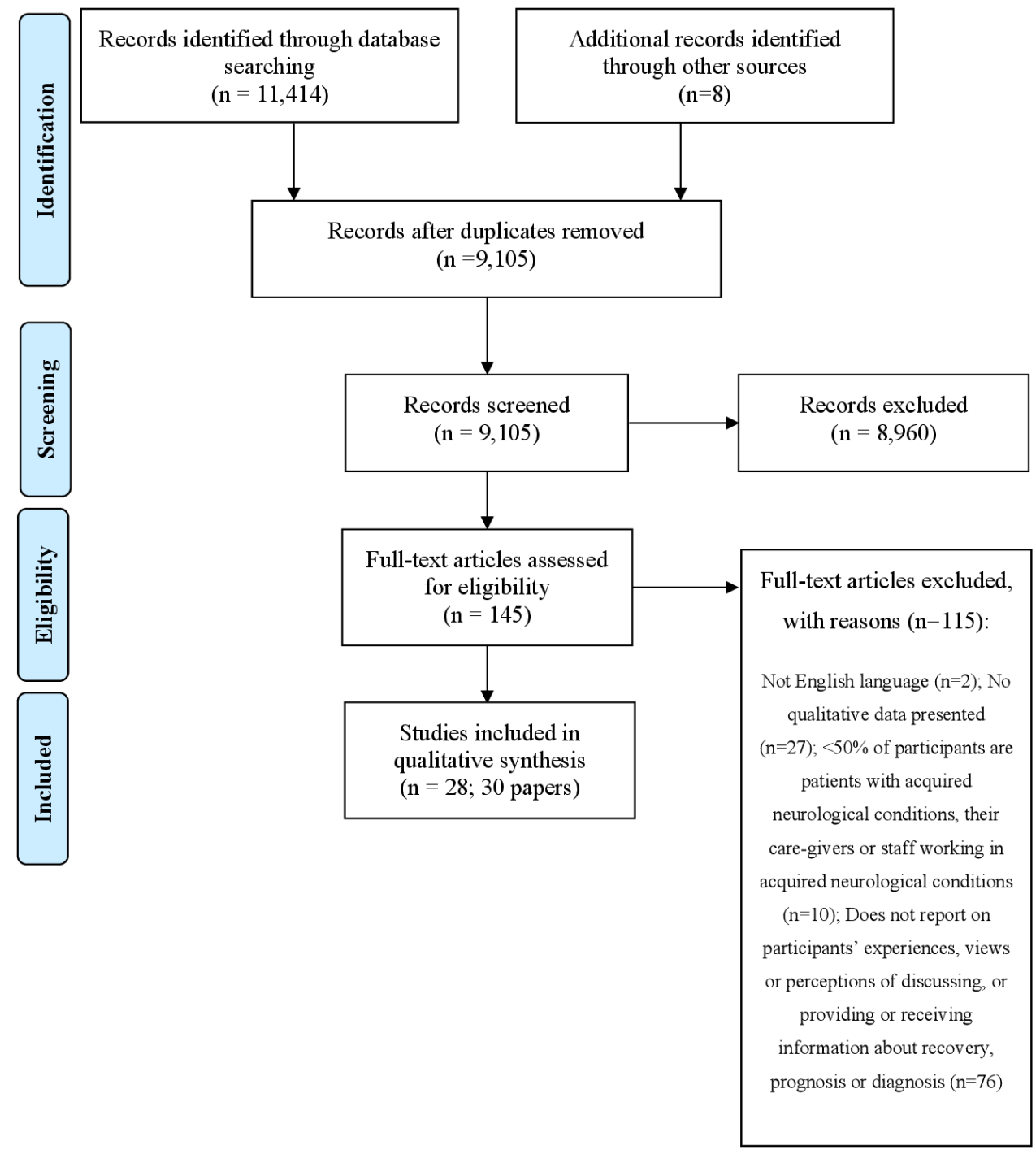

Figure 1 Preferred Reporting Items for Systematic Reviews and Meta-Analyses flow diagram of study selection.

community (n=11), ${ }^{26-28} 3335363839424446$ while a minority took place across multiple settings: inpatient and outpatient $(\mathrm{n}=2),{ }^{22} 2341$ inpatient and community $(\mathrm{n}=3),{ }^{12} 202143$ and two included HCPs from a range of settings, including inpatient, outpatient and community. ${ }^{34} 37$ Of note, two studies were conducted in palliative care settings; one involved multiple neurological conditions (described above), ${ }^{41}$ the other involved TBI. ${ }^{30}$

Five studies included data from only individuals with the condition, ${ }^{28} 35394446$ four reported views of only caregivers, ${ }^{16253143}$ and four included perspectives of both individuals with the condition and caregivers. ${ }^{26} 273638$ Seven included only HCPs, including physiotherapists, ${ }^{34}$ occupational therapists, ${ }^{12}$ speech and language therapists, ${ }^{37}$ nurses ${ }^{40}$ doctors and nurses ${ }^{45}$ or a mixture of therapists, ${ }^{33}$ or a wider mix of HCPs. ${ }^{17}$ Three included individuals with the condition and HCPs,${ }^{22-24} 32$ one included caregivers and HCPs, ${ }^{29}$ and four included all three groups. ${ }^{20} 21304142$ Participant demographic data from the included studies are presented in tables 2 and 3 .
In terms of data collection, most studies used semistructured interviews $(\mathrm{n}=17),{ }^{12} 242527$ 29-31 34 36-39 42-46 and three used focus groups. ${ }^{20212635}$ One used a survey, ${ }^{28}$ and one analysed a video-taped observation. ${ }^{32}$ Seven used mixed-methods: three employed focus groups and interviews ${ }^{17} 4041$; one each used interviews and questionnaires, ${ }^{16}$ observations and interviews, ${ }^{22}{ }^{23}$ and a questionnaire and observations. ${ }^{33}$

\section{Quality assessment}

Table 4 details the methodological quality of included studies. Most $(n=20)$ were scored + or ++ , suggesting that all/most or some of the criteria were met, and where there was insufficient description the conclusions would be unlikely to change. Of the eight studies deemed to be of lower quality, four lacked richness of the data presented. ${ }^{27} 284446$ In four, the context from which the data were drawn was unclear, 33374041 and in three, the analysis did not appear sufficiently rigorous. ${ }^{334046}$ In three studies, research methodology was not adequately justified, ${ }^{32}$ data collection methods 


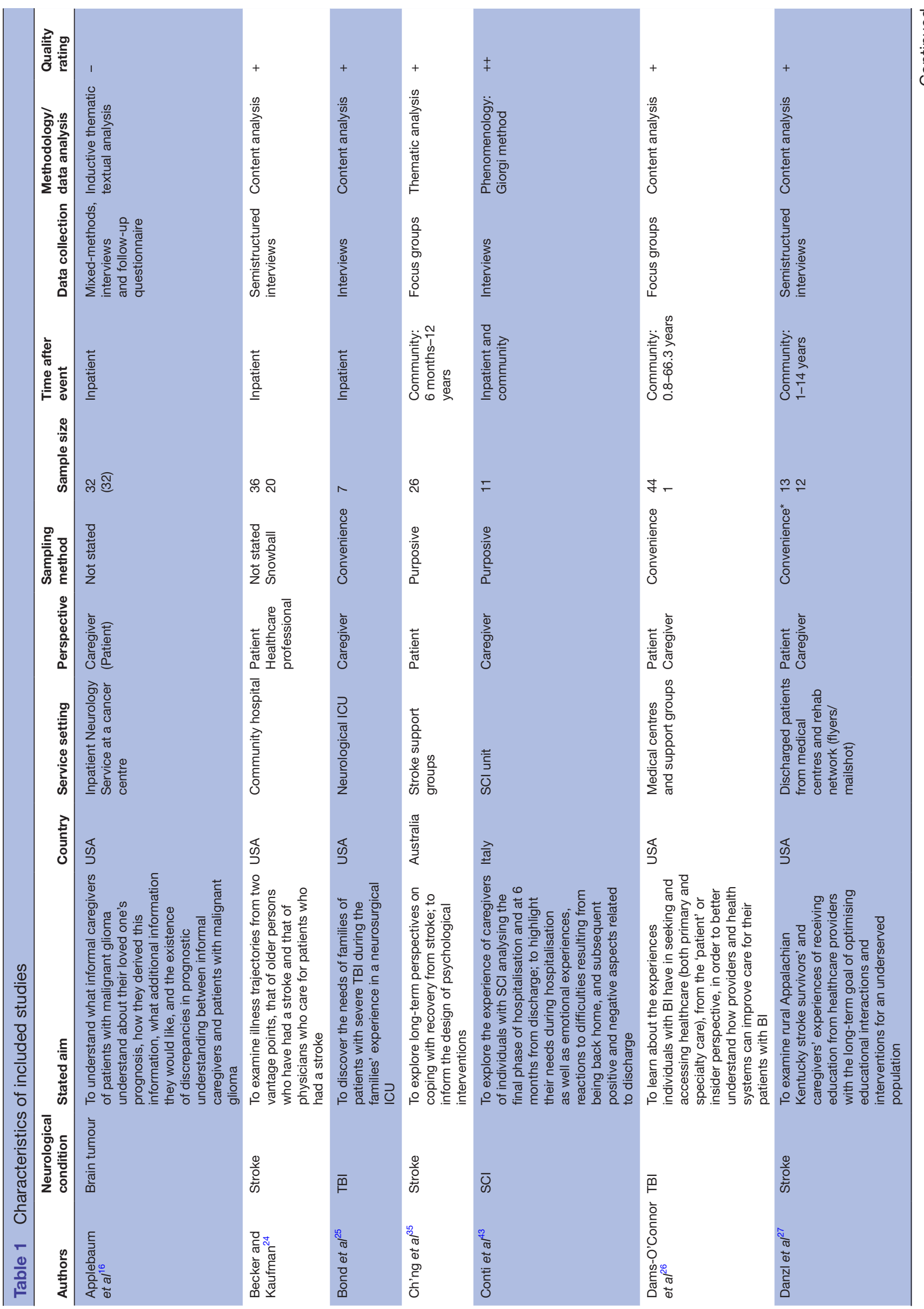

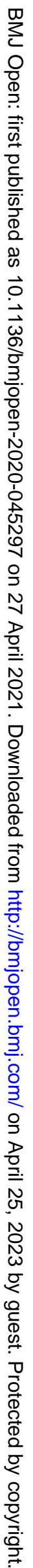




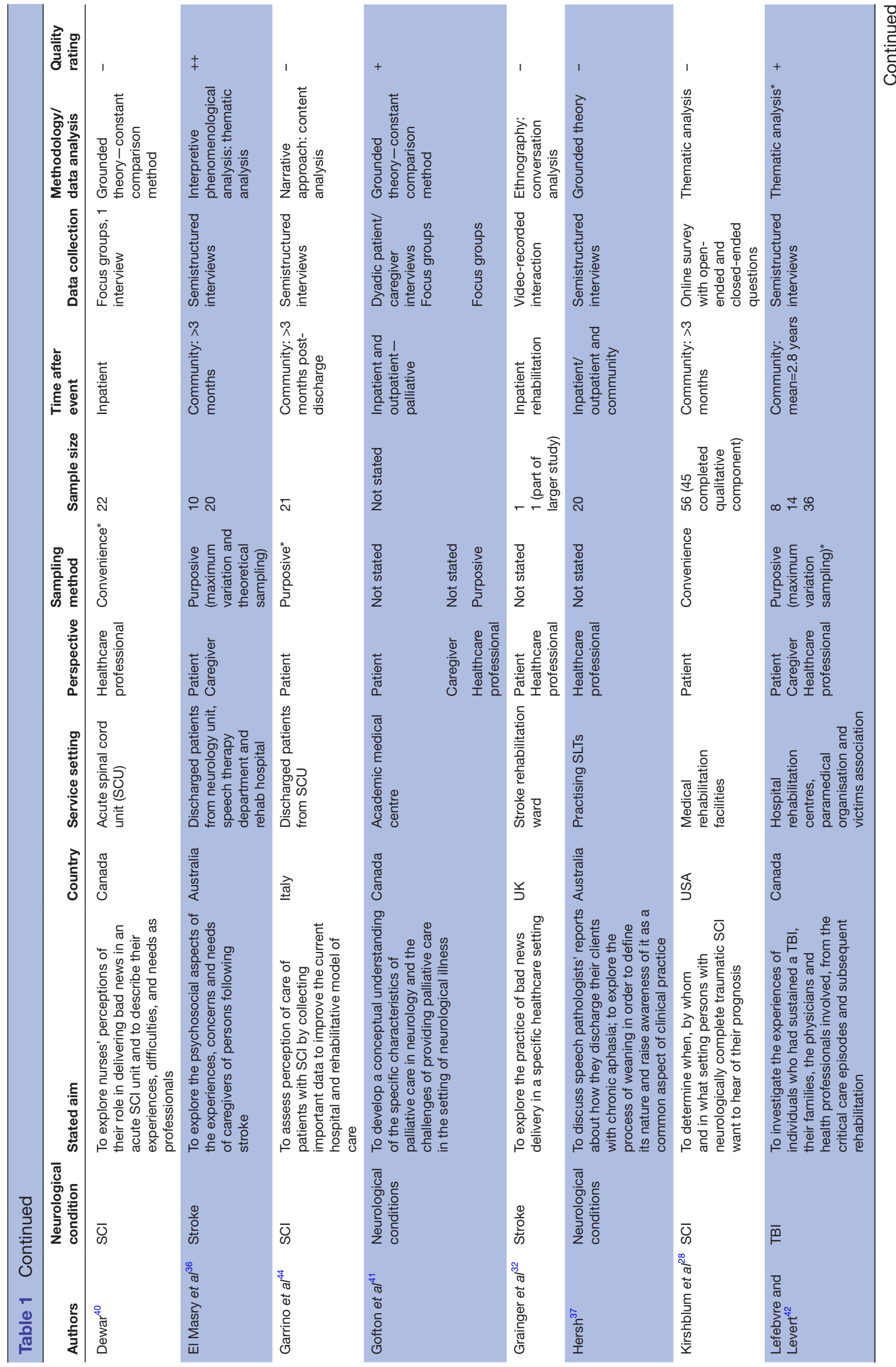

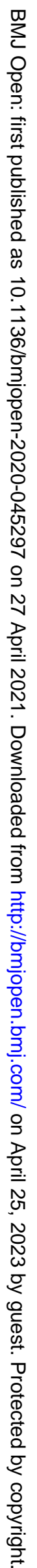




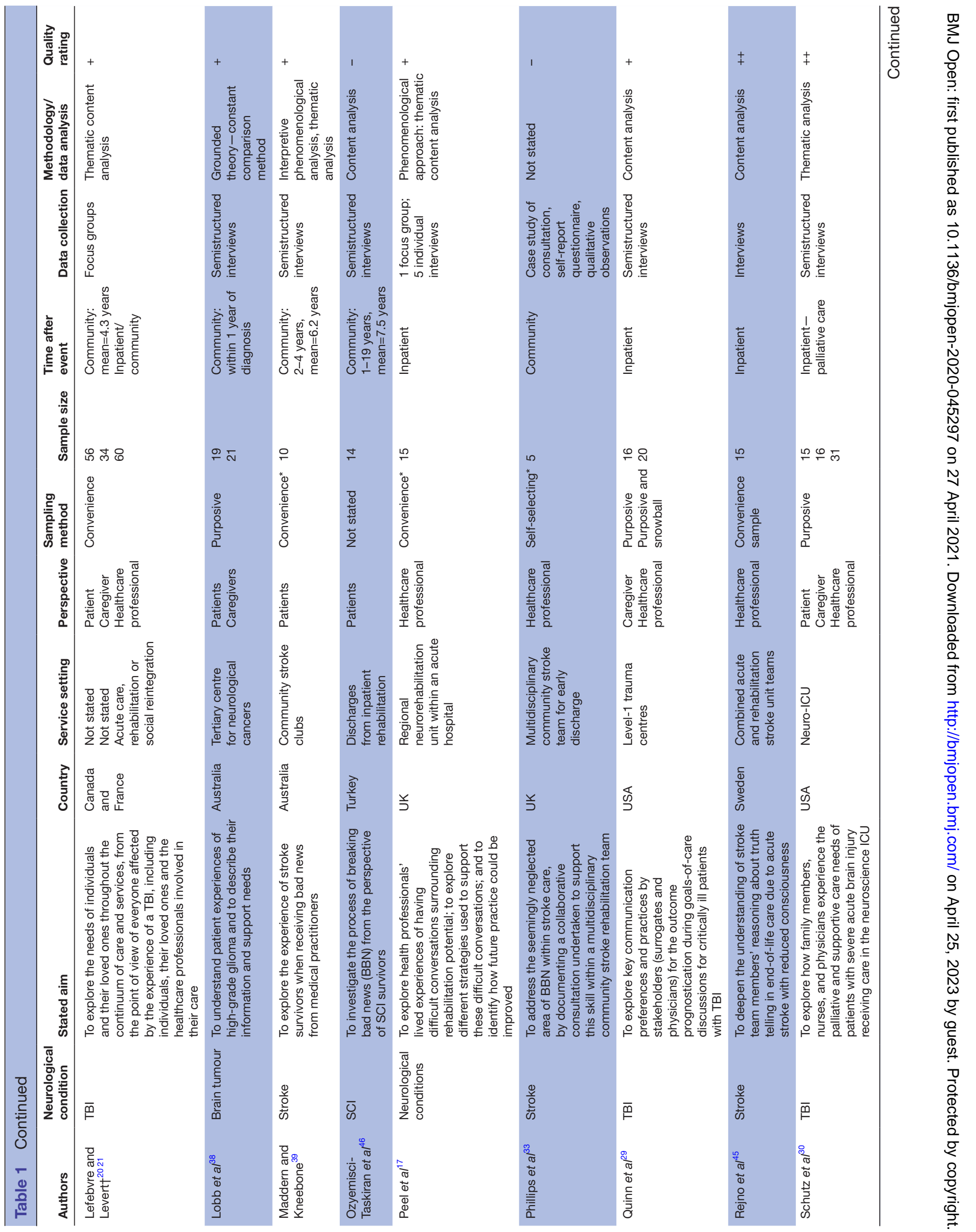




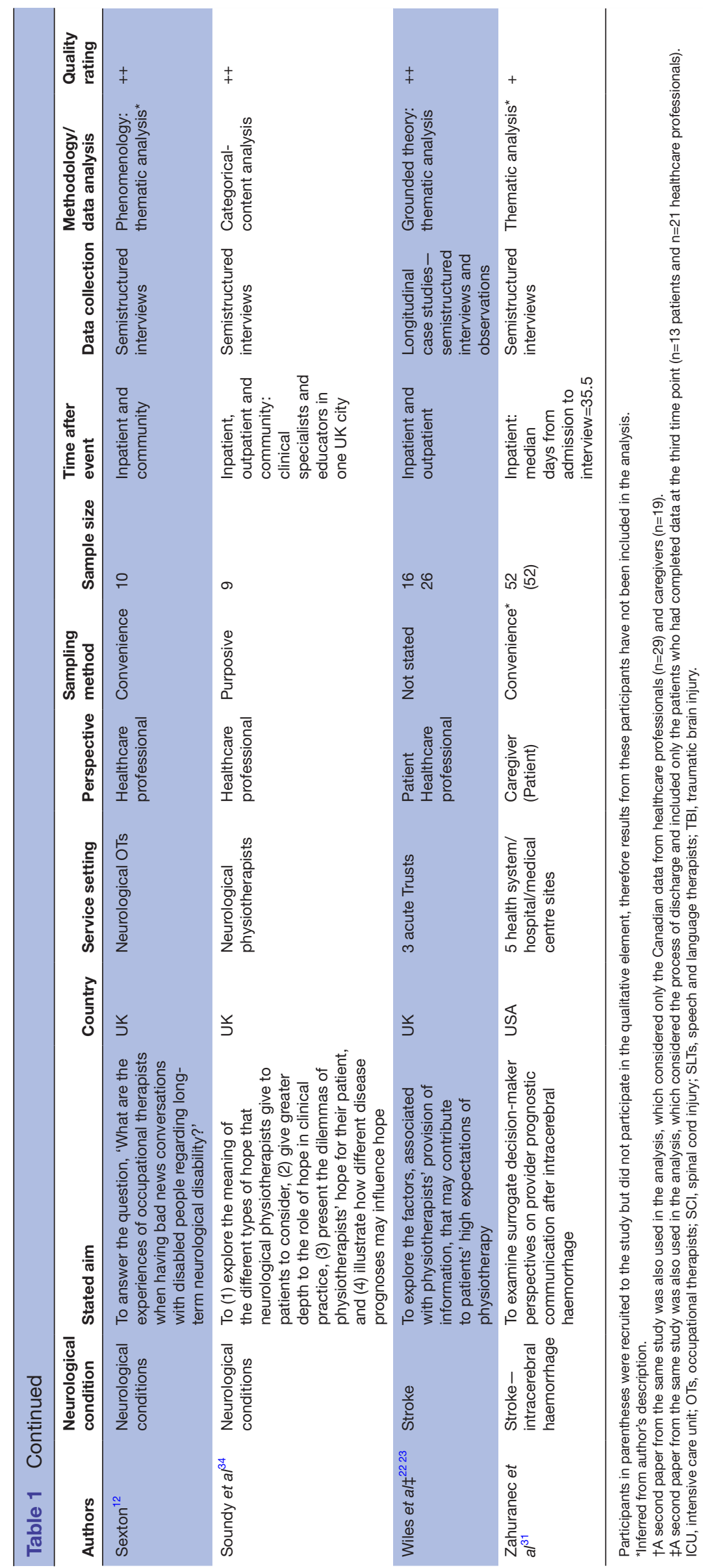

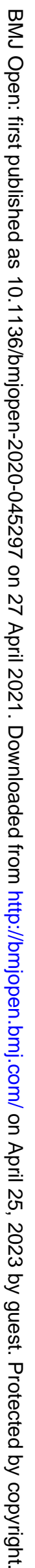


Table 2 Included studies, patient and carer demographics

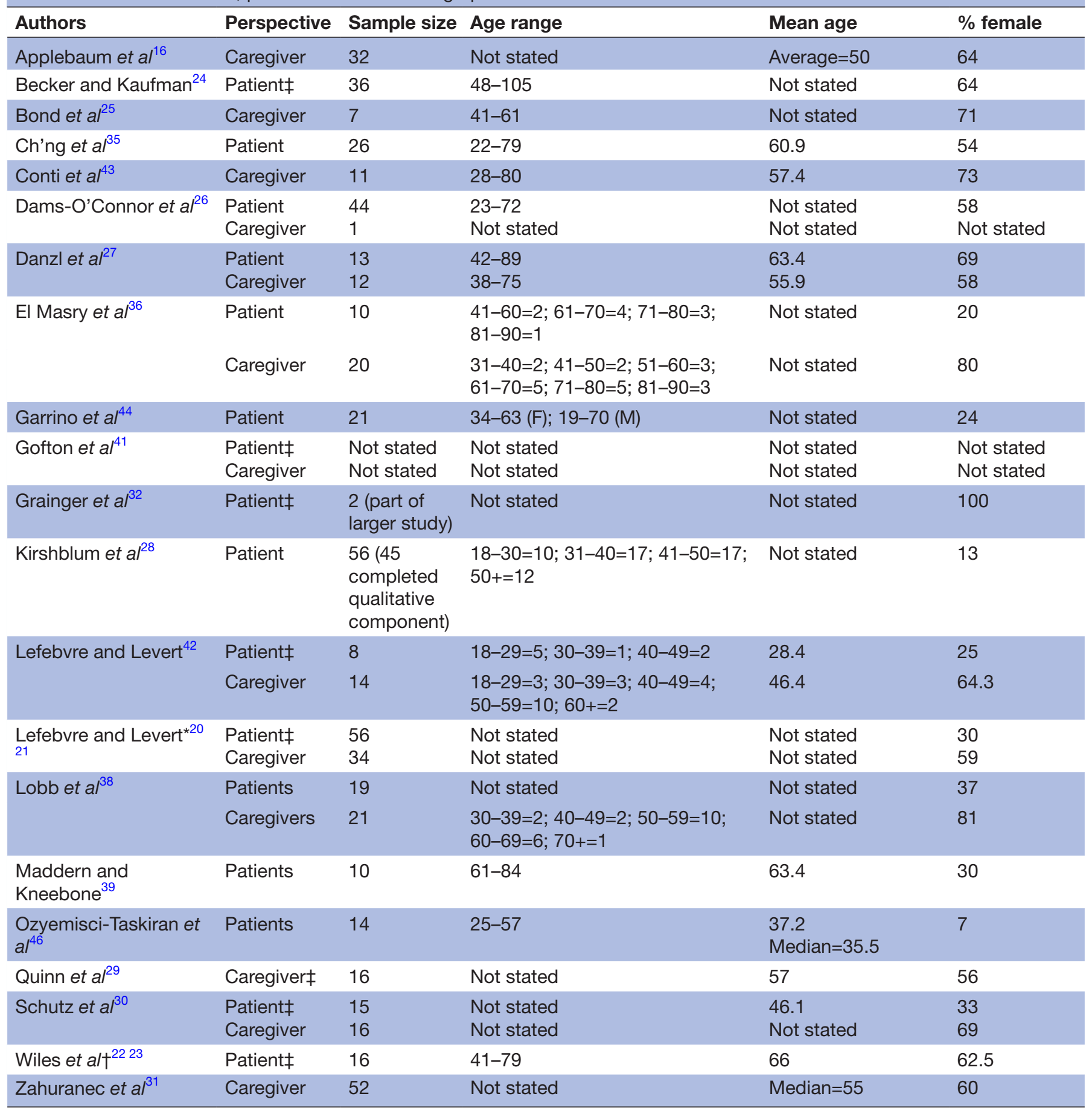

*A second paper from the same study was also included, with 19 caregivers, age range $=28-67$, mean 50.6 years.

$\dagger$ A second paper from the same study was also included, with 13 patients of the same age range/mean age, $61.5 \%$ female.

¥Study also included healthcare professionals (see table 3 ).

were not clearly described, ${ }^{32}$ methods were felt to be unreliable, ${ }^{40}$ or the links between the findings and conclusions were unclear. ${ }^{28}$

\section{Thematic synthesis}

Eleven descriptive themes were generated from the synthesis and gave rise to five analytical themes, ${ }^{13}$ reflecting patient, caregiver and HCPs' experiences of receiving and providing information about recovery. Descriptive themes are outlined in figure 2; the five analytical themes are considered in detail below:

The right information at the right time

In general, patients and families across studies wanted to receive information about their diagnosis and recovery prognosis from their treating medical teams. ${ }^{202124254344}$ 


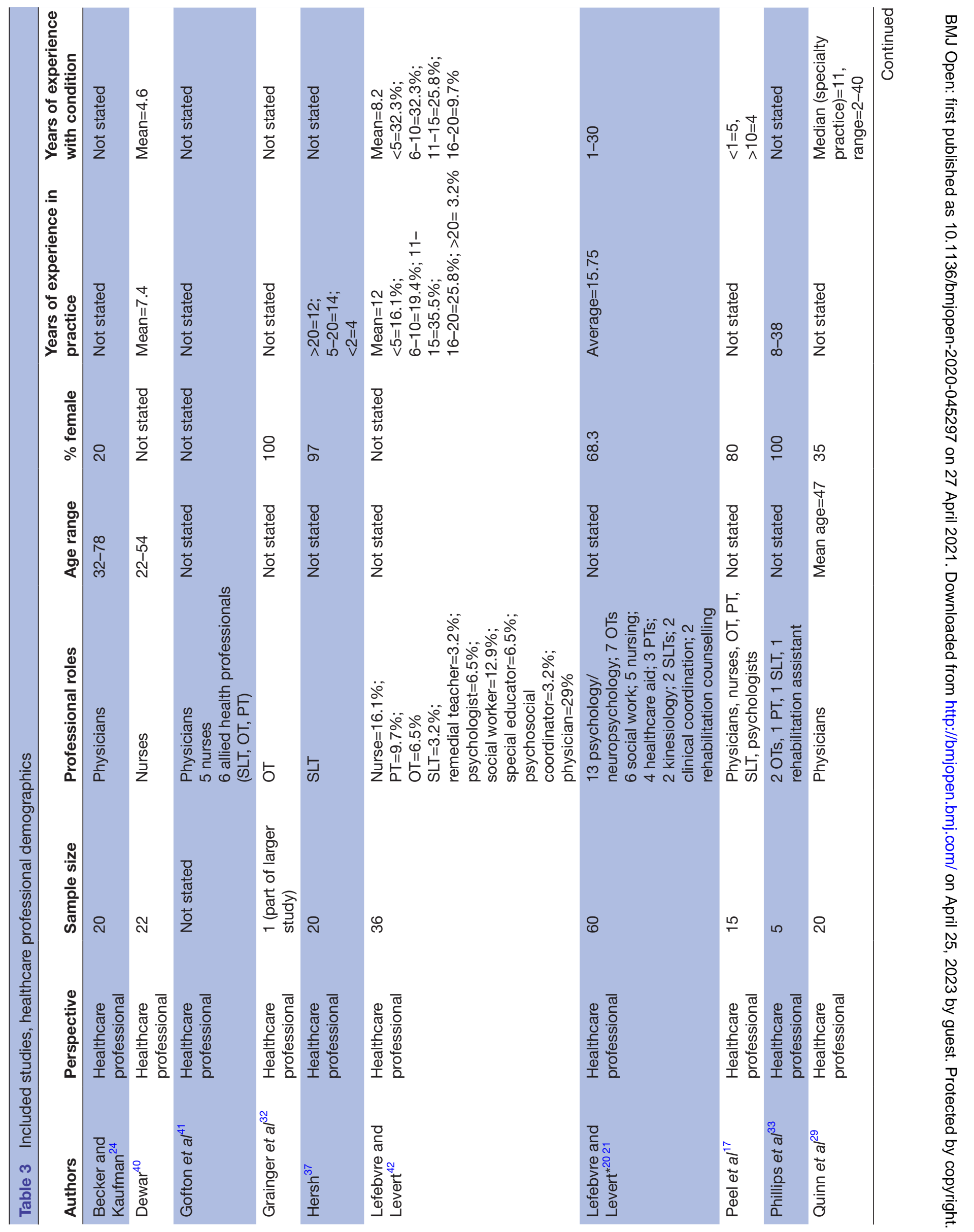


This usually included information about the nature of the patient's condition, the cause, available treatments, and the prognosis or long-term prospects. However, there was some variation in what was deemed to be the 'right' information across conditions and individuals. Patients with SCI particularly wanted clear information about their diagnosis, ${ }^{43}$ while patients who had a stroke or a TBI commonly wanted information about their recovery potential, including how long this would take and their long-term outcome. ${ }^{20} 2124$ In contrast, some patients with tumours did not wish to receive prognostic information (usually in relation to a life-limiting condition) ${ }^{1638}$ :

[...] when we met with the doctor, it seemed she wanted to reveal to us where we stood, and I interrupted her, and said that I really do not want to, I cannot hear that so please do not share that with me. (Caregiver, brain tumour) ${ }^{16}$

Overall, a source of dissatisfaction for patients and caregivers across numerous studies was a feeling that they did not receive enough information from their healthcare teams. ${ }^{2021} 26272935363839424346$ Complaints included HCPs not being proactive in providing information ${ }^{27} 42$ or not providing timely information. ${ }^{20} 212639$ Patients and caregivers described negative emotions associated with not receiving information including frustration, 20212943 worry, ${ }^{39}$ caregiver stress, ${ }^{43}$ delay in acceptance and adjustment, ${ }^{42}$ and decreased trust in, and poorer relationships with, their treating HCPs. ${ }^{29} 42$ Consistency in approach and language across different HCPs was viewed as essential, with concerns raised when different professionals provided incongruous information. ${ }^{25} 2931$

The timing of information provision was also a key concern for patients and caregivers. In the acute phase after TBI, stroke or SCI, for example, in the emergency room, information was often provided to families, due to the medical status of the patient. However, even where patients were medically stable, the nature of an unexpected neurological event or diagnosis meant that they or their families often felt unable to understand or retain information effectively in the early period after the event, due to their emotional state of mind, that is, feeling overwhelmed or in shock 20212627353842 :

In [the hospital], my wife was away for a moment when the nurses were doing their rounds, but my mom was there. And they gave her a bunch of handouts... And I think they may have explained a little bit about brain injury. But my mom wasn't quite in the head-space to remember all of it at the time. [...] (Patient with TBI) ${ }^{26}$

Some patients and caregivers accepted these limitations and described how they wanted information to be repeated at different time points. ${ }^{26}$ For HCPs, however, this presented a challenge: they were aware of these difficulties, ${ }^{20} 214042$ but feared complaints from patients and caregivers who felt that information was not satisfactorily provided. ${ }^{42}$ Suggested strategies to manage this 
Table 4 Methodological quality of included studies

\begin{tabular}{|c|c|c|c|}
\hline & Appropriate & Not sure & Inappropriate \\
\hline \multirow[t]{2}{*}{ 1. Theoretical approach: appropriateness } & 28 & 0 & 0 \\
\hline & Clear & Mixed & Unclear \\
\hline \multirow[t]{2}{*}{ 2. Theoretical approach: clarity } & 24 & 4 & 0 \\
\hline & Defensible & Not sure & Indefensible \\
\hline \multirow[t]{2}{*}{ 3. Research design/methodology } & 10 & 17 & 1 \\
\hline & Appropriately & Not sure/inadequately reported & Inappropriately \\
\hline \multirow[t]{2}{*}{ 4. Data collection } & 14 & 13 & 1 \\
\hline & Clearly described & Not described & Unclear \\
\hline \multirow[t]{2}{*}{ 5. Trustworthiness: role of the researcher } & 4 & 24 & 0 \\
\hline & Clear & Not sure & Unclear \\
\hline \multirow[t]{2}{*}{ 6. Trustworthiness: context } & 15 & 9 & 4 \\
\hline & Reliable & Not sure & Unreliable \\
\hline \multirow[t]{2}{*}{ 7. Trustworthiness: reliable methods } & 7 & 20 & 1 \\
\hline & Rigorous & Not sure/not reported & Not rigorous \\
\hline \multirow[t]{2}{*}{ 8. Analysis: rigorous } & 16 & 9 & 3 \\
\hline & Rich & Not sure/not reported & Poor \\
\hline \multirow[t]{2}{*}{ 9. Analysis: rich data } & 17 & 7 & 4 \\
\hline & Reliable & Not sure/not reported & Unreliable \\
\hline \multirow[t]{2}{*}{ 10. Analysis: reliable } & 9 & 19 & 0 \\
\hline & Convincing & Not sure & Not convincing \\
\hline \multirow[t]{2}{*}{ 11. Analysis: convincing } & 23 & 5 & 0 \\
\hline & Relevant & Partially relevant & Irrelevant \\
\hline \multirow[t]{2}{*}{ 12. Analysis: relevance to aims } & 24 & 4 & 0 \\
\hline & Adequate & Not sure & Inadequate \\
\hline \multirow[t]{2}{*}{ 13. Conclusions } & 24 & 3 & 1 \\
\hline & Appropriate & Not sure/not reported & Inappropriate \\
\hline \multirow[t]{2}{*}{ 14. Ethics } & 19 & 9 & 0 \\
\hline & ++ & + & - \\
\hline Overall assessment & 7 & 13 & 8 \\
\hline
\end{tabular}

situation included repetition of information at different times, ${ }^{262742}$ provision of written materials, ${ }^{26}$ and providing staff contact details for patients and families to contact if they had questions at a later time. ${ }^{26}$

HCPs agreed that the timing of information about recovery potential needed to be right for the individual patient and caregiver, suggesting that they needed to be 'ready' to hear it, ${ }^{12}$ or they risked causing anger or distress. ${ }^{33}$ Some studies, particularly those involving stroke survivors, suggested that some patients could reject or deny information about recovery provided when they were not ready to hear it, particularly where it was perceived to be negative and challenged their hopes of returning to their previous lifestyle 2223333946 :

I just thought, I'll be all right, I'll be all right... the people told me that you will get aphasia and that you're going to have that for the rest of your life and I thought, yeah, I'll be over that in a couple of weeks' time, and never did [get over it]. (Patient who had a stroke $)^{39}$

Some HCPs felt that the most important time to provide information was during rehabilitation (although of note, no studies included the rehabilitation of patients with brain tumours), when patients receive therapy to help them regain their independence, with some suggesting 'drip-feeding' it over time, ${ }^{173740}$ or providing it in the context of a formal meeting ${ }^{17}$ :

In the back of your mind, you've got some rough plan of 'I don't think she is really going to ever get functional verbal speech' so you do your other stuff along the way to try and bring them to that point as well. (Speech and language therapist) $^{37}$

In some cases, the practicalities of discharge forced therapists to discuss recovery towards the end of rehabilitation, ${ }^{22} 23$ particularly where a patient's home 


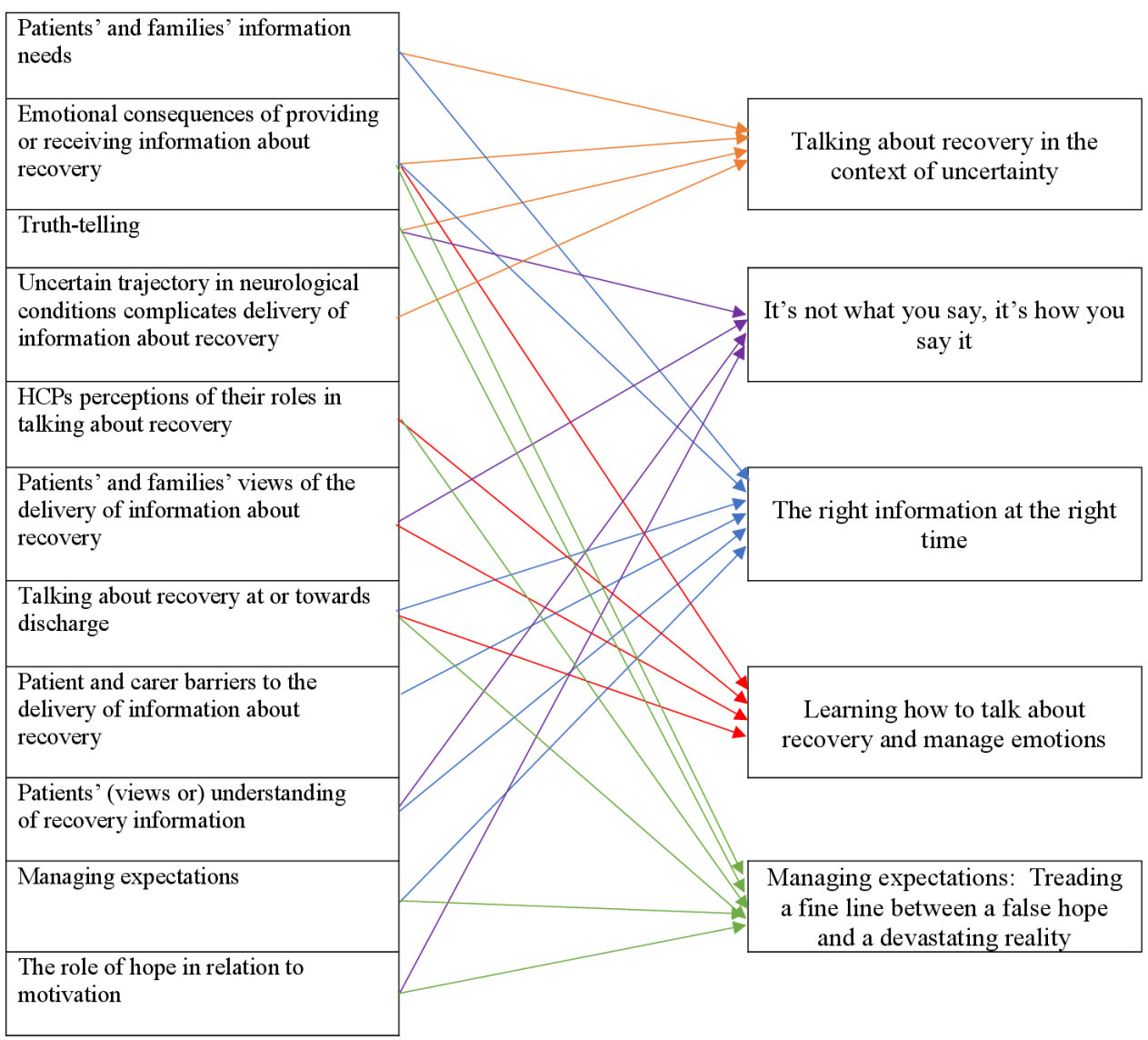

Figure 2 Descriptive and analytical themes. HCPs, healthcare professionals.

environment was deemed unsuitable or their care needs had increased ${ }^{1232}$ :

The patient perhaps isn't safe to go home anymore $\ldots$ and we were recommending placement, and that's always hard to discuss with people. (Occupational therapist, inpatient neurology) ${ }^{12}$

Where patients and particularly caregivers felt they did not receive the right information about recovery from HCPs, they sought it from other sources. ${ }^{16} 202146$ Most commonly, alternative sources included use of the internet,${ }^{1617202146}$ and books and newspapers. ${ }^{202134}$ Human sources of information included fellow patients and their families, ${ }^{1746}$ and skilled relatives or friends. ${ }^{20} 213946$ Occasionally, HCPs expressed concern about the use of additional sources, worrying that information could provide false hope, particularly where the information did not pertain to the individual's specific case. ${ }^{1734}$

\section{Managing expectations: treading a fine line between false hope and a devastating reality}

This theme relates only to studies in TBI, SCI, stroke and general neurology settings; none of the included studies considered rehabilitation after brain tumour.

Although HCPs felt that during rehabilitation was the best time to discuss recovery potential, this was sometimes problematic. During rehabilitation, patients were mostly engaged in therapy and motivated to work hard. While HCPs endeavoured to be realistic in the information they provided, they were aware that receiving potentially 'bad news' about how much (or how little) a patient might achieve in the long term could be distressing and demotivating. As a result, they were concerned about the impact negative information could have on patients' mood, hope and subsequently motivation to participate in rehabilitation $^{12} 1724333440$; a feeling which was echoed by some patient and caregiver participants. ${ }^{39}$ HCPs feared that a loss of motivation could result in a negative prediction becoming a self-fulfilling prophecy:

I just don't want to sort of squash their hope ... they sort of give up a lot and also they don't maintain their home exercise programme. (Occupational therapist, community rehabilitation $)^{43}$

These fears could result in HCPs being unwilling or hesitating to discuss recovery with patients and families. ${ }^{12} 24$

At the opposite end of the spectrum, HCPs also feared that a failure to manage patients' and families' expectations about recovery and provide realistic information could foster 'false hope', and allow patients' and families' to maintain expectations of a return to life as they had experienced it before their neurological 
event. ${ }^{12} 222329303442$ They worried that patients, and their families, would be disappointed or distressed if their hopes for recovery were not realised..$^{22} 232934$ As a result, HCPs knew they must provide some realistic information to manage patients' and carers' expectations, but expressed that they must do so in a way that nurtured their patients' hope and motivation; this was presented as

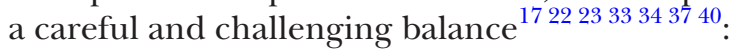

You wouldn't want to give them too high hopes, but then you also want to encourage them [...] (Neurological physiotherapist) $^{34}$

HCPs described several strategies they used to manage the expectations of patients and their caregivers. In the acute phase, they could provide written information about the role of rehabilitation and what could be provided by their service. ${ }^{17}$ During rehabilitation, therapists described how realistic goal-setting ${ }^{1234} 37$ and repetition of information about recovery in different forms (written, via keyworker or outreach service) ${ }^{17}$ could help to manage expectations about what it might be possible to achieve. Where expectations were effectively managed, HCPs described benefits in enabling carers to plan for the future $^{12}$ and in facilitating discharge ${ }^{37}$; however, where patients maintained what HCPs deemed to be unrealistic hopes for recovery, they felt this limited adjustment to disability. 2223

Underlying discussions about recovery appeared to be an assumption made by patients that they would make a full recovery, and that their main route to recovery was through rehabilitation. Where this was the case, they perceived discharge as an end to their recovery, and expressed disappointment if it occurred before their recovery expectations were met. ${ }^{22}{ }^{23}$ In contrast, HCPs understood recovery as a long-term process, with its conclusion likely involving adaptations to a patient's previous lifestyle. In a minority of studies, however, it was not simply the outcome of rehabilitation about which HCPs and patients were observed to have incongruous ideas, but also their understanding of the process. While HCPs described that what could be achieved through therapy was mediated by spontaneous neurological recovery, only two studies described how this was conveyed to patients and families, ${ }^{22-24}$ and this concept was rarely mentioned by patient and family participants. ${ }^{22} 2327$ Patients and families, therefore, placed much emphasis on patients' motivation and effort within rehabilitation, which could result in feelings of failure if their expected level of recovery was not achieved. ${ }^{20}{ }^{21}$ Rather than discussing the complexities of rehabilitation with patients and families, HCPs attempted to bring patients' and families' expectations and perspectives about recovery closer to their own so that they were 'on the same page' ${ }^{30}{ }^{32}$ Strategies employed by HCPs at discharge when patients felt they had not achieved their expected recovery included negotiation of a finite number of treatment sessions or the use of objective measures to demonstrate to the patient that they were no longer making progress and thus persuade them that more therapy would not be beneficial to their recovery. ${ }^{22} 2337$

\section{It's not what you say, it's how you say it}

Where HCPs feared both giving false optimism and destroying hope, patients and families described how important hope was to them. ${ }^{16}$ Where information about recovery was provided, patients and families felt that HCPs should deliver it with compassion and empathy, ${ }^{20} 2127-29383946$ as well as positivity, allowing them to maintain hope and motivation 2021283036383946 :

I think they need to be more in empathy with the patient rather than just a number. (Patient who had a stroke $)^{39}$

They wanted positive messages, including a focus on the function the patient retained, rather than what they had lost ${ }^{28}$ :

I would prefer the initial statement to be addressing the positive aspect of the condition, e.g., "you are capable of doing almost all you did before the accident'. (Patient with SCI) ${ }^{28}$

This presentation of 'good news' alongside bad news was observed, ${ }^{32}$ and also acknowledged as a strategy by some HCPs. ${ }^{40}$ Patients and caregivers expressed a need to feel listened to and understood, with their distress acknowledged. ${ }^{26} 273946$ A private setting for information provision was important, and patients valued being able to choose whether their families were present or not. ${ }^{28} 46$ Sometimes, however, patients and caregivers felt HCPs were too negative in the messages they gave, resulting in distress, anxiety, fear or anger. ${ }^{30}$ Where bad experiences were recounted, they involved receiving incongruous information from different $\mathrm{HCPs},{ }^{25} 2931$ overhearing information, ${ }^{46}$ not being given an opportunity to ask questions $^{2021} 3946$ or the use of complex medical terminology, which limited their understanding of the information. ${ }^{20} 2131$

Patients and caregivers also described a desire for truthful and honest information about recovery, ${ }^{2021} 25$ 28-30 and HCPs felt that telling the truth was important to build relationships, gain families' trust and maintain their own credibility ${ }^{4045}$ :

I can take the bad news. Just don't tell us things that are not true and think that we need to hear happy things. (Caregiver, TBI) ${ }^{25}$

For HCPs, a consistent approach to conveying information could help patients to process and understand what had happened to them, accept residual disability and adjust to necessary lifestyle changes. ${ }^{1734}{ }^{37}$ It was also crucial to developing a trusting relationship between patients, their families and HCPs. ${ }^{20} 2142$ The use of inconsistent language between HCPs and the expression of different viewpoints could have negative effects on caregivers, including causing distress and confusion, ${ }^{31}$ causing them to doubt the truth of what HCPs were 
telling them, ${ }^{25} 31$ triggering arguments among families, ${ }^{25}$ and resulting in stress and anxiety in decision-making. ${ }^{29} 31$ In some studies, participants suggested having one key contact in the patient's family and one on the healthcare team, or providing written information, could aid consistency. 17202125

\section{Learning how to talk about recovery and manage emotions}

Most professionals described a role in talking about recovery (with the exception of brain tumours; no included studies involved HCPs working with patients with brain tumour), and in breaking bad news, including physicians and therapists, ${ }^{12} 1724303337$ although none advocated a team approach. Nurses did not take outright ownership of this role, choosing to defer to physicians or therapists, ${ }^{30}{ }^{40}$ although some described how the roundthe-clock nature of their work meant they were well placed and available to answer patients' questions when information provided by other HCPs had had time to 'sink in'. ${ }^{40}$

Although therapists described a role in talking about recovery, they described lacking sufficient training or confidence, worried patients would not listen to them and felt uncomfortable answering questions outside of their expertise. ${ }^{12} 1733$ In terms of the knowledge and skills required, therapists and nurses felt communication skills were important to effectively discuss recovery with patients and families, as well as knowledge about, and ability to predict, potential outcomes. ${ }^{12} 17333440$ Most felt that learning to break bad news was experience based, rather than provided via formal training, ${ }^{12} 17$ although some expressed an unfulfilled need for training. ${ }^{12} 173342$ Where training was desired, therapists wanted it to be led by experienced colleagues, and suggested techniques such as role-play, supervision and debriefing, and reflective practice. Provision of staff support groups ${ }^{12}$ and access to clinical guidelines were also felt to be important. ${ }^{17}$ In terms of content, therapists wanted training to include the grieving process and breaking bad news. ${ }^{17}$ Access to training was not discussed by physicians in the included studies, perhaps because such training is now commonly provided as part of medical education.

Where HCPs (therapists, nurses and physicians) talked about their experiences delivering information about recovery, and particularly, breaking bad news, they often described an emotional cost. Their emotional reactions ranged from awkwardness and discomfort, to worry and stress, as well as feelings of responsibility or failure $^{1217222340-42}$ :

We are dealing with long term disability and we're almost dealing with the acute stages of anger and coming to terms, [it] can be really emotionally hard for the therapist as well. (HCP, inpatient neurorehabilitation $)^{17}$

I wonder if there is a sense ... almost that you have failed the patient. (Occupational therapist, inpatient neurology $)^{12}$
HCPs described that these conversations became easier with experience and identified reflective practice and debriefing with team members as ways to manage their emotions. 121740

Patients and caregivers also described their emotional responses to discussions about recovery. This was often related to receiving 'bad news', and included shock (at diagnosis), ${ }^{38}{ }^{42}$ fear, $^{39}$ anger, ${ }^{39}{ }^{46}$ distress ${ }^{35} 3946$ and anxiety. ${ }^{35}$ In some cases, the way that information about recovery or bad news was presented provoked a negative emotional response, for example, where patients felt the HCPs provided the information in a rushed or patronising manner, they could experience anger or anxiety. ${ }^{39} \mathrm{In}$ addition to delivering information about recovery, HCPs described a role in managing the resulting emotional reactions of patients and families. ${ }^{1722} 2333404245$ They described how strategies such as detaching themselves from the situation and talking about their own feelings could help ${ }^{42}$; however, some described withholding information or avoiding having conversations with patients or families to limit their emotional response. ${ }^{42} 45$

\section{Talking about recovery in the context of uncertainty}

Before being able to convey information about recovery and prognosis to patients and their families, and thus meet their information needs, HCPs must feel able to make predictions about how the trajectory of an acquired neurological condition might progress for a specific individual. To do this, some described using clinical evidence or results of medical investigations, while others relied on their previous clinical experience; however, they often felt that outcomes were still uncertain. ${ }^{22-24} 3441$ Across studies, HCPs discussed how uncertainty impacted their ability and willingness to share their predictions with patients and their families. They described how, although they might have a hunch or an instinct about how much recovery a patient was likely to achieve based on their previous experience, it was not always possible to generalise across cases, and they might encounter exceptions ${ }^{2434} 37$ :

I do find that most families, or the person themselves wants to know how much is this going to improve ... how quickly that's going to happen? And I usually say 'well, I don't know, everybody is different' and in my own mind I have probably already got a gut feeling of how much change they are going to make, as in actual change on testing ... but it is not usually something that I would verbalise ... because you do get the surprises. (Speech and language therapist) ${ }^{37}$

HCPs dealt with this uncertainty in different ways. Many were afraid to convey predictions about recovery to patients and their families for fear of being wrong, and therefore giving false hope, causing disappointment and anger if their predictions did not come to pass; or quashing hope unnecessarily. ${ }^{22} 23$ 40-42 They feared that the information provided would be 'used against them' by patients and families and worried about damaging 
relationships. 222942 As a result, some HCPs described how they might avoid or delay providing information about recovery 22330333742 ; which did not go unnoticed by patients. ${ }^{42}{ }^{44}$ Many provided vague information or made attempts to convey the uncertainty they faced ${ }^{20-2429} 3742$ :

The prognosis is never certain, and when you don't know, you have to tell them you don't know. (HCP, TBI $)^{20}$

I just own it. I just say I'm not sure[...]Usually I'll have a hunch, that it is going to go one way or the other, but I readily and openly cop to not being sure and not knowing. (Physician, critically ill TBI) ${ }^{29}$

Some HCPs felt that sharing their uncertainty could instil realism in patients and families, thus avoiding false hope, but could help patients to maintain the hope that they needed to keep them engaged and motivated in rehabilitation. ${ }^{24} 3437$

The extent to which patients and their families accepted the uncertainty presented to them varied across individuals. While some were able to accept it, ${ }^{22-24} 3144$ others found uncertainty resulted in feelings of frustration,

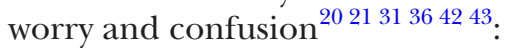

I don't know what he is going to be able to do. It made me anxious I guess is probably the best way to describe it. I wanted answers and they really were not able to give me answers. (Caregiver of patient with intracerebral haemorrhage $)^{31}$

The inability to see what the future might hold could make them feel helpless and impotent; the trajectory appeared outside of their control, and the endpoint was unclear. ${ }^{24} 43$

However, some families did find hope in the uncertainty presented to them. ${ }^{30}{ }^{31}$ The 'not knowing' of what may occur gave them space to hope for a positive outcome. Some described sympathy for the HCPs, who they believed were trying their best in an uncertain situation ${ }^{44}$ :

Doctors never committed themselves by saying you will never walk again. However, the poor things really didn't know what to say. (Patient with SCI) ${ }^{44}$

From the perspective of HCPs, some felt that patients and families generally could understand the uncertainty they were facing as professionals, while others accepted that uncertainty could cause frustration or distress. ${ }^{3742}$

\section{DISCUSSION}

This study demonstrates the difficulties inherent in talking about recovery after neurological events. Although patients and caregivers desire more information about an individual's potential for recovery, a triad of factors impact HCPs' efforts to meet these needs, namely the uncertain trajectory of recovery, a desire to maintain patients' hope and motivation in rehabilitation, and typically an absence of training to discuss recovery and break bad news. Where information is provided, patients and caregivers emphasise that it should be delivered honestly, with kindness and compassion, and most of all, positivity.

It is unsurprising that our findings indicate that patients and caregivers report unmet needs for information: this finding is common within the neurological literature. ${ }^{47-50}$ However, our findings suggest that it may be unclear whether information provision did not occur or whether information was provided but patients and caregivers were unable to retain it, due to the shock of diagnosis, or cognitive or communication problems resulting from neurological damage, or to understand it; due to complexities in medical language. Future studies should use both interviews and observations of clinical practice to ascertain this. The timing of information provision is also important and past research has recognised how patients' and families' information needs may change. For example, the 'Timing it right' framework describes how caregivers of patients who had a stroke are initially concerned with information about whether the patient's condition is life-threatening, and following stabilisation of their medical condition, thoughts turn to whether and how much functional recovery is possible ${ }^{51}$ Our findings suggest that HCPs should be encouraged to consider proactively asking patients and families whether and what types of information they would prefer at different times before providing it. However, they should be aware of potential difficulties in absorbing or retaining information, particularly when provided in acute settings, and therefore consider providing written materials or contact details of HCPs where appropriate.

Our study highlights the need for consistency in the communication of recovery information to patients and families, with poorer experiences reported following receipt of different information from different HCPs. Although not unexpected in the context of an uncertain recovery trajectory, it is imperative that multidisciplinary team members are clear about their roles in discussing recovery and that the messages they provide correspond with those of their colleagues. While prognostication is traditionally seen as the role of doctors and this is appropriate particularly where disease is life-limiting, our study has highlighted the key role that other team members play in discussing recovery in neurorehabilitation. Therapists contribute specific knowledge about functional recovery and their roles in therapy provision and goalsetting require them to manage expectations about what can be achieved through rehabilitation. Nurses are also well placed to answer patients' questions about recovery, although they may defer questions to other professionals, ${ }^{40}$ and this could potentially result in missed opportunities for communication or increase patients' anxiety. Nurses' concerns about discussing recovery with patients with neurological conditions and their families have previously been documented, ${ }^{40} 52$ despite an identified role in providing information to help patients and families make sense of the impact of their event to facilitate adjustment. ${ }^{53}$ Future interventions should encourage 
a team-based approach to talking about recovery, and consider ways to ensure that individual conversations are appropriately shared via documentation or team meetings.

HCPs' concerns about destroying hope when trying to instil realistic expectations were evident in our study, demonstrating their awareness of the psychological impact that information about recovery, and the way it is presented, can have on patients and caregivers. Our findings highlight patients' and families' desire for empathetic and compassionate delivery of information, particularly when receiving bad news. Approaches to communicating bad news are available ${ }^{545}$ providing recommendations, including how to prepare a patient and manage their subsequent emotions. Training incorporating these models using techniques, such as roleplay and group discussions, have been demonstrated to be effective in increasing clinicians' confidence $^{5657}$ and patient satisfaction.$^{58}$ Given the roles played by therapists in talking about recovery in neurological settings identified by our review, it is perhaps surprising that only one study recognised the use of such models in their training ${ }^{33}$ and they described breaking bad news as a skill they were expected to have but learnt only through experience. Future training interventions would benefit from inclusion of specific communication skills to help therapists manage conversations about recovery in ways which meet the needs of patients and their families. The role of experiential learning should be supported through the inclusion of training or shadowing opportunities specific to recovery conversations for newly qualified therapists or those new to neurological settings.

The emotional cost to HCPs involved in discussing recovery has also been highlighted in our study. Some research has explored the emotional well-being of HCPs working in neurological rehabilitation, and it has been suggested that the frequent undertaking of emotional conversations with patients (who might display behavioural symptoms and have interpersonal problems) and their families could be linked to occupational stress and burnout. ${ }^{59-61}$ Identified solutions to such stress for HCPs include clinical supervision, organisational and professional support and strong team relationships, ${ }^{5962}$ some of which were also identified as facilitators of talking about recovery in our study. Future interventions should promote awareness of these issues and encourage practices such as debriefing and reflective practice to help HCPs manage their emotions.

\section{Strengths and limitations}

To our knowledge, this is the first systematic review to synthesise patients', caregivers' and HCPs' views and experiences of talking about recovery in acquired neurological conditions. The synthesis of qualitative studies using rigorous methods has allowed us to understand and synthesise the perspectives of the three groups of participants in recovery conversations, which is key to developing an intervention which is acceptable to, and meets the needs of, all parties and can be effectively implemented into clinical practice.

A limitation of our study is that the validity and relevance of our findings are dependent on the quality and reporting of the included studies. Appraising the quality of qualitative research is a contentious issue, both in terms of whether and how it should be completed. ${ }^{63} \mathrm{We}$ employed a widely used tool, which was designed to assess the quality of evidence to make recommendations for inclusion in public health guidance. ${ }^{18}$ Although we did not use quality assessment to exclude studies from our review, all the included studies were considered worthy of inclusion, as they made a valuable contribution to the synthesis.

Although we were able to compare and contrast the findings of papers considering the views of patients, carers and HCPs with a single acquired neurological condition, we included five papers, which reported the views and experiences of HCPs who worked with patients with a range of neurological diagnoses. This precluded further exploration relating to specific conditions. It may also be possible that HCPs who had contact with patients with both acquired and progressive conditions may have had slightly different views about talking to patients and carers about recovery, than those solely working with those with acquired conditions. However, such is the nature of clinical training that it is likely that the HCP participants in all studies may have had previous experiences in other clinical areas which may have informed their views.

We employed a robust search strategy with backwards and forwards citation searching to identify articles for inclusion; however, the use of inconsistent terminology in this field, and in qualitative research in general, means that some eligible titles may have been missed. Additionally, the inclusion of only studies published in English may have resulted in the omission of the experiences of patients, caregivers and HCPs reported in different languages.

\section{Implications for future research}

Our study has implications for the design of interventions to improve conversations about recovery in acquired neurological conditions. However, although research has explored views and perceptions of discussions about recovery, there is little empirical evidence about the effects of interventions. Future research and the evaluation of interventions should also consider whether talking about recovery in a structured way can impact outcomes such as patient satisfaction, mood and adjustment to disability when compared with standard care, and whether specific training for staff could improve confidence and experiences.

\section{Author affiliations}

${ }^{1}$ Academic Unit for Ageing and Stroke Research, University of Leeds, Leeds, UK ${ }^{2}$ Academic Unit for Ageing and Stroke Research, Bradford Institute for Health Research, Bradford Teaching Hospitals NHS Foundation Trust, Bradford, UK ${ }^{3}$ School of Psychology, University of Leeds Faculty of Biological Sciences, Leeds, UK 
${ }^{4}$ Bradford Institute for Health Research, Bradford Teaching Hospitals NHS Foundation Trust, Bradford, UK

${ }^{5}$ School of Public Health and Community Medicine, University of New South Wales,

Sydney, New South Wales, Australia

${ }^{6}$ Division of Nursing, Midwifery and Social Work, The University of Manchester, Manchester, UK

Acknowledgements The authors thank Deirdre Andre for help designing the search strategy and Mark Perry for assistance in developing the protocol. The authors also thank Gregg Rawlings for help with citation screening and Ellie Grant for assisting with double data extraction.

Contributors L-JB, DC and ST conceived of the study. L-JB conducted the searches. Screening was completed by L-JB and AF. DC and JJ acted as consensus reviewers. L-JB and FW extracted data and assessed quality of the included papers. $\mathrm{L}-\mathrm{JB}$ was responsible for the data analysis, with input from DC, AF and TFC. The initial draft of the manuscript was prepared by L-JB, then circulated among all authors for critical revision.

Funding This work was supported by The Stroke Association's Postgraduate Fellowship programme (grant number: TSA PGF 2017-02)

Competing interests None declared.

Patient consent for publication Not required.

Ethics approval Ethical approval was not required, as no primary data were collected as part of this study.

Provenance and peer review Not commissioned; externally peer reviewed.

Data availability statement The data extracted from papers included in the systematic review are already published and in the public domain.

Supplemental material This content has been supplied by the author(s). It has not been vetted by BMJ Publishing Group Limited (BMJ) and may not have been peer-reviewed. Any opinions or recommendations discussed are solely those of the author(s) and are not endorsed by BMJ. BMJ disclaims all liability and responsibility arising from any reliance placed on the content. Where the content includes any translated material, BMJ does not warrant the accuracy and reliability of the translations (including but not limited to local regulations, clinical guidelines, terminology, drug names and drug dosages), and is not responsible for any error and/or omissions arising from translation and adaptation or otherwise.

Open access This is an open access article distributed in accordance with the Creative Commons Attribution Non Commercial (CC BY-NC 4.0) license, which permits others to distribute, remix, adapt, build upon this work non-commercially, and license their derivative works on different terms, provided the original work is properly cited, appropriate credit is given, any changes made indicated, and the use is non-commercial. See: http://creativecommons.org/licenses/by-nc/4.0/.

\section{ORCID iDs}

Louisa-Jane Burton http://orcid.org/0000-0003-3617-1410

Anne Forster http://orcid.org/0000-0001-7466-4414

Judith Johnson http://orcid.org/0000-0003-0431-013X

Thomas F. Crocker http://orcid.org/0000-0001-7450-3143

Sarah F. Tyson http://orcid.org/0000-0001-6301-8791

Faye Wray http://orcid.org/0000-0001-9351-5019

David J. Clarke http://orcid.org/0000-0001-6279-1192

\section{REFERENCES}

1 The Neurological Alliance. Neuro numbers, 2019. Available: https:// www.neural.org.uk/assets/pdfs/neuro-numbers-2019.pdf

2 Turner-Stokes L, Pick A, Nair A, et al. Multi-Disciplinary rehabilitation for acquired brain injury in adults of working age. Cochrane Database Syst Rev 2015;29.

3 Fehlings MG, Tetreault LA, Wilson JR, et al. A clinical practice guideline for the management of acute spinal cord injury: introduction, rationale, and scope. Global Spine Journal 2017;7:84S-94.

4 Intercollegiate Stroke Working Party. National clinical guideline for stroke. 5th edition. London: Royal College of Physicians, 2016.

5 Khan F, Amatya B, Ng L, et al. Multidisciplinary rehabilitation after primary brain tumour treatment. Cochrane Database Syst Rev 2015:CD009509.

6 Graham M. Burying our mistakes: dealing with prognostic uncertainty after severe brain injury. Bioethics 2020;34:612-9.
7 Holloway RG, Gramling R, Kelly AG. Estimating and communicating prognosis in advanced neurologic disease. Neurology 2013;80:764-72.

8 Fallowfield L, Jenkins V. Communicating sad, bad, and difficult news in medicine. Lancet 2004;363:312-9.

9 Stinear CM. Prediction of motor recovery after stroke: advances in biomarkers. Lancet Neurol 2017;16:826-36.

10 Dalkilic T, Fallah N, Noonan VK, et al. Predicting injury severity and neurological recovery after acute cervical spinal cord injury: a comparison of cerebrospinal fluid and magnetic resonance imaging biomarkers. J Neurotrauma 2018;35:435-45.

11 Lueckel SN, Stephen AH, Monaghan SF. Predicting outcomes in acute traumatic brain injury (TBI). R I Med J 2019;102:34-6.

12 Sexton D. 'As good as it's going to get'. bad news conversations in neurology: challenges for occupational therapists. British Journal of Occupational Therapy 2013;76:270-9.

13 Thomas J, Harden A. Methods for the thematic synthesis of qualitative research in systematic reviews. BMC Med Res Methodol 2008;8:45.

14 Tong A, Flemming K, Mclnnes E, et al. Enhancing transparency in reporting the synthesis of qualitative research: ENTREQ. BMC Med Res Methodol 2012;12:181.

15 Walsh RA, Girgis A, Sanson-Fisher RW. Breaking bad news. 2: what evidence is available to guide clinicians? Behav Med 1998;24:61-72

16 Applebaum AJ, Buda K, Kryza-Lacombe M, et al. Prognostic awareness and communication preferences among caregivers of patients with malignant glioma. Psychooncology 2018;27:817-23.

17 Peel R, Jones S, Miller C, et al. Great expectations? A qualitative study of health professionals' perspectives on breaking bad news about rehabilitation potential after traumatic brain injury or spinal injury. Disabil Rehabil 2020;42:3209-14.

18 National Institute for Health and Care Excellence. Methods for the development of NICE public health guidance (third edition), 2012. Available: https://www.nice.org.uk/process/pmg4/chapter/15appendix-h-quality-appraisal-checklist-qualitative-studies

19 Barnett-Page E, Thomas J. Methods for the synthesis of qualitative research: a critical review. BMC Med Res Methodol 2009;9:1-11.

20 Lefebvre $\mathrm{H}$, Levert M-J. The close relatives of people who have had a traumatic brain injury and their special needs. Brain Inj 2012;26:1084-97.

21 Lefebvre $\mathrm{H}$, Levert MJ. The needs experienced by individuals and their loved ones following a traumatic brain injury. J Trauma Nurs 2012;19:197-207.

22 Wiles R, Ashburn A, Payne S, et al. Discharge from physiotherapy following stroke: the management of disappointment. Soc Sci Med 2004;59:1263-73.

23 Wiles R, Ashburn A, Payne S, et al. Patients' expectations of recovery following stroke: a qualitative study. Disabil Rehabil 2002;24:841-50.

24 Becker G, Kaufman SR. Managing an uncertain illness trajectory in old age: patients' and physicians' views of stroke. Med Anthropol Q 1995:9:165-87.

25 Bond AE, Draeger CRL, Mandleco B, et al. Needs of family members of patients with severe traumatic brain injury. Implications for evidence-based practice. Crit Care Nurse 2003;23:63-72.

26 Dams-O'Connor K, Landau A, Hoffman J, et al. Patient perspectives on quality and access to healthcare after brain injury. Brain Inj 2018;32:431-41.

27 Danzl MM, Harrison A, Hunter EG, et al. "A lot of things passed me by": rural stroke survivors' and caregivers' experience of receiving education from health care providers. J Rural Health 2016;32:13-24.

28 Kirshblum SC, Botticello AL, DeSipio GB, et al. Breaking the news: a pilot study on patient perspectives of discussing prognosis after traumatic spinal cord injury. J Spinal Cord Med 2016;39:155-61.

29 Quinn T, Moskowitz J, Khan MW, et al. What families need and physicians deliver: contrasting communication preferences between surrogate decision-makers and physicians during outcome prognostication in critically ill TBI patients. Neurocrit Care 2017;27:154-62.

30 Schutz REC, Coats HL, Engelberg RA, et al. Is there hope? is she there? how families and clinicians experience severe acute brain injury. J Palliat Med 2017;20:170-6.

31 Zahuranec DB, Anspach RR, Roney ME, et al. Surrogate decision makers' perspectives on family members' prognosis after intracerebral hemorrhage. J Palliat Med 2018;21:956-62.

32 Grainger KP, Masterson S, Jennings M. 'Things aren't the same, are they?': The management of bad news delivery in the discourse of stroke care. Commun Med 2005;2:35-44.

33 Phillips J, Kneebone II, Taverner B. Breaking bad news in stroke rehabilitation: a consultation with a community stroke team. Disabil Rehabil 2013:35:694-701. 
34 Soundy A, Smith B, Butler M, et al. A qualitative study in neurological physiotherapy and hope: beyond physical improvement. Physiother Theory Pract 2010;26:79-88.

35 Ch'ng AM, French D, McLean N. Coping with the challenges of recovery from stroke: long term perspectives of stroke support group members. J Health Psychol 2008;13:1136-46.

36 El Masry Y, Mullan B, Hackett M. Psychosocial experiences and needs of Australian caregivers of people with stroke: prognosis messages, caregiver resilience, and relationships. Top Stroke Rehabil 2013;20:356-68.

37 Hersh D. "Weaning" clients from aphasia therapy: Speech pathologists' strategies for discharge. Aphasiology 2003;17:1007-29.

38 Lobb EA, Halkett GKB, Nowak AK. Patient and caregiver perceptions of communication of prognosis in high grade glioma. $J$ Neurooncol 2011:104:315-22.

39 Maddern R, Kneebone II. Receiving bad news: a thematic analysis of stroke survivor experiences. J Patient Exp 2019;6:271-7.

40 Dewar A. Nurses' experiences in giving bad news to patients with spinal cord injuries. J Neurosci Nurs 2000;32:324-30.

41 Gofton TE, Chum M, Schulz V, et al. Challenges facing palliative neurology practice: a qualitative analysis. J Neurol Sci 2018;385:225-31.

42 Lefebvre $\mathrm{H}$, Levert MJ. Breaking the news of traumatic brain injury and incapacities. Brain Inj 2006;20:711-8.

43 Conti A, Garrino L, Montanari P, et al. Informal caregivers' needs on discharge from the spinal cord unit: analysis of perceptions and lived experiences. Disabil Rehabil 2016;38:159-67.

44 Garrino L, Curto N, Decorte R, et al. Towards personalized care for persons with spinal cord injury: a study on patients' perceptions. $J$ Spinal Cord Med 2011;34:67-75.

45 Rejnö Åsa, Silfverberg G, Ternestedt B-M. Reasoning about truthtelling in end-of-life care of patients with acute stroke. Nurs Ethics 2017;24:100-10.

46 Ozyemisci-Taskiran O, Coskun O, Budakoglu II, et al. Breaking bad news in spinal cord injury; a qualitative study assessing the perspective of spinal cord injury survivors in turkey. J Spinal Cord Med 2018;41:347-54.

47 Sinnakaruppan I, Williams DM. Family carers and the adult headinjured: a critical review of carers' needs. Brain Inj 2001;15:653-72.

48 Hafsteinsdóttir TB, Vergunst M, Lindeman E, et al. Educational needs of patients with a stroke and their caregivers: a systematic review of the literature. Patient Educ Couns 2011;85:14-25.

49 Kersten P, George S, McLellan L, et al. Met and unmet needs reported by severely disabled people in southern England. Disabil Rehabil 2000;22:737-44.
50 Cox RJ, Amsters DI, Pershouse KJ. The need for a multidisciplinary outreach service for people with spinal cord injury living in the community. Clin Rehabil 2001;15:600-6.

51 Cameron JI, Gignac MAM. "Timing It Right": a conceptual framework for addressing the support needs of family caregivers to stroke survivors from the hospital to the home. Patient Educ Couns 2008;70:305-14.

52 Oyesanya TO, Bowers BJ, Royer HR, et al. Nurses' concerns about caring for patients with acute and chronic traumatic brain injury. $J$ Clin Nurs 2018;27:1408-19.

53 Kirkevold $\mathrm{M}$. The role of nursing in the rehabilitation of stroke survivors: an extended theoretical account. ANS Adv Nurs Sci 2010;33:E27-40.

54 Buckman RA. Breaking bad news: the S-P-I-K-E-S strategy. Community Oncol 2005;2:138-42.

55 Villagran M, Goldsmith J, Wittenberg-Lyles E, et al. Creating comfort: a communication-based model for breaking bad news. Commun Educ 2010;59:220-34.

56 Baile WF, Kudelka AP, Beale EA, et al. Communication skills training in oncology. description and preliminary outcomes of workshops on breaking bad news and managing patient reactions to illness. Cancer 1999;86:887-97.

57 Park I, Gupta A, Mandani K, et al. Breaking bad news education for emergency medicine residents: a novel training module using simulation with the spikes protocol. J Emerg Trauma Shock 2010;3:385

58 McCluskey L, Casarett D, Siderowf A. Breaking the news: a survey of ALS patients and their caregivers. Amyotroph Lateral Scler Other Motor Neuron Disord 2004;5:131-5.

59 Wittig PG, Tilton-Weaver L, Patry BN, et al. Variables related to job satisfaction among professional care providers working in brain injury rehabilitation. Disabil Rehabil 2003;25:97-106.

60 Schlenz KC, Guthrie MR, Dudgeon B. Burnout in occupational therapists and physical therapists working in head injury rehabilitation. Am J Occup Ther 1995;49:986-93.

61 Broom JP, Williams J. Occupational stress and neurological rehabilitation physiotherapists. Physiotherapy 1996;82:606606-14614.

62 Ewen C, Jenkins H, Jackson C, et al. Well-Being, job satisfaction, stress and burnout in speech-language pathologists: a review. Int $J$ Speech Lang Pathol 2020:1-11.

63 Mays N, Pope C. Assessing quality in qualitative research. BMJ 2000;320:50-2. 